\title{
Review
}

\section{Genetic structure and diversity of the wild Ussurian pear in East Asia}

\author{
Hironori Katayama*1), Hitomi Amo ${ }^{1)}$, Tana Wuyun²), Chiyomi Uematsu ${ }^{3)}$ and Hiroyuki Iketani ${ }^{4)}$ \\ 1) Food Resources Education and Research Center, Faculty of Agriculture, Kobe University, 1348 Uzurano, Kasai, Hyogo 675-2103, Japan \\ 2) Paulownia Research and Development Center of China, Non-timber Forestry Research and Development of CAF, Weiwu Road, \\ Zhengzhou City 450003, China \\ 3) Botanical Gardens, Graduate School of Science, Osaka City University, 2000 Kisaichi, Katano, Osaka 576-0004, Japan \\ 4) NARO Institute of Fruit Tree Science, 2-1 Fujimoto, Tsukuba, Ibaraki 305-8605, Japan
}

The Ussurian pear is the most important cultivated pear in the northern part of China. Cultivated Ussurian pears are considered to have derived from Pyrus ussuriensis Maxim. which is native to the northeast of China. In Japan, two varieties of $P$. ussuriensis, P. ussuriensis var. aromatica and var. hondoensis are native to the northern area and the central area of the main island respectively. In order to reveal the origin of Pyrus ussuriensis var. aromatica distributed in the northern area of main island of Japan, more than 40 explorations have been performed in Japan and in China, and more than 30 natural habitats were recognized. These natural habitats are at risk of extinction because of human development and forest degradation caused by climate change. Population structure and genetic diversity of $P$. ussuriensis in China and P. ussuriensis var. aromatica in Japan have been investigated using both morphological and molecular markers in order to define appropriate conservation units, and to provide a good focus for conservation management. Distant evolutionary relationships between P. ussuriensis Maxim. in China and P. ussuriensis var. aromatica in Japan inferred from population genetic structure and phylogenetic analysis are also discussed.

Key Words: Pyrus ussuriensis, Pyrus ussuriensis var. aromatica, Ussurian pear, conservation, population genetics, introgression, SSR.

\section{Introduction}

Pears, which are cultivated throughout the temperate regions and have spread all over the world, belong to the genus Pyrus in the tribe Pyreae of subfamily Spiraeoidae in the Rosaceae (Campbell et al. 2007). The genus Pyrus is considered to have originated during the Tertiary period (65-55 million years ago) in the mountain regions of southwestern China (Bell et al. 1996). In East Asia, the major cultivated pears are classified traditionally into three species, Pyrus ussuriensis Maxim., P. bretschneideri Rehder, and P. pyrifolia (Burm. f.) Nakai (Gu and Sponberg 2003, Yü and $\mathrm{Ku}$ 1974). Several types of cultivar generally corresponding to these botanical classifications have been recognized in horticulture; the Ussurian pear referred to as $P$. ussuriensis, the Chinese white pear referred to as P. bretschneideri, the Chinese sand pear, and the Japanese pear referred to as P. pyrifolia (Bell et al. 1996, Yü 1979).

P. ussuriensis (Ussurian pear) known with aromatic fruit

Communicated by M. Omura

Received October 1, 2015. Accepted January 25, 2016.

*Corresponding author (e-mail: hkata@kobe-u.ac.jp) volatiles is the most important cultivated pear in the northern part of China (Kang et al. 2010, Li et al. 2013, 2014, Qin et al. 2012). More than 150 cultivars are known to have originated from this species. Cultivated Ussurian pears are considered to be derived from $P$. ussuriensis which is native to the northern part of China ( $\mathrm{Pu}$ and Wang 1963).

Ussurian pear is native to the north eastern part of China, the far east of Russia, the northern part of the Korean Peninsula, and the north eastern part of the main island of Japan (Gu and Sponberg 2003, Maximowicz 1859). In China, wild P. ussuriensis trees grow in Heilongjiang, Jilin, Liaoning, Inner Mongolia, Heibei, Shandong, and Shanxi (Jiao et al. 2000, Wuyun et al. 2013). The CAAS report (Report of the Chinese Academy of Agricultural Science 1963) described how wild Ussurian pear trees were distributing from Shuangfeng to Jiameng in Heilongjiang Province, especially abundant in the Yichun forest farms of Heilongjiang Province.

However the forests in Heilongjiang and Jilin are being harmed by human development, so that the habitats of the wild Ussurian pear are decreasing. On the other hand, in Inner Mongolia, there has been little rainfall for the past 30 years, which has led to serious drought damage, desertification and 
soil degeneration (Wuyun et al. 2013). Consequently wild Ussurian pears in Inner Mongolia are decreasing. According to research by Ma et al. (2011) and Wuyun et al. (2013), there were over 1,000 wild Ussurian pear trees in six natural habitats in 2009, but about two thirds of those trees have now been killed by drought after a shortage of rainfall for more than 100 days in 2010 (Wuyun et al. 2013). Therefore, conservation is urgently required.

The characteristics, which can distinguish wild Chinese Ussurian pear from other Pyrus species are as follows; (1) Morphological features: short peduncle and pedicel, usually 1 to $2 \mathrm{~cm}$ (Gu and Sponberg 2003). (2) Cold resistance : this species can endure a temperature of $-52^{\circ} \mathrm{C}$. (3) After ripening, their eating quality can improve (Yü 1979). But the classification of cultivated Ussurian pears in China is problematic. Although floristic studies adopted the short fruit pedicel $(<2 \mathrm{~cm})$ in order to discriminate $P$. ussuriensis from P. pyrifolia and P. bretschneideri (Gu and Sponberg 2003), many cultivars with longer fruit pedicels have been classified as P. ussuriensis in horticultural literature (Iketani et al. 2012, Yü 1979).

In Japan, in the early 20th century, as two new native species of $P$. ussuriensis with aromatic volatiles in the fruit were described from two distantly located regions (Nakai 1918): P. hondoensis Nakai et Kikuchi from the central area and $P$. aromatica Kikuchi et Nakai from the northern part of the main island in Japan. Later Ohwi (1965) recognized these as two varieties of $P$. ussuriensis i.e., $P$. ussuriensis var. hondoensis and P. ussuriensis var. aromatica, respectively. As indicated by its Latin name, 'aromatica', good aroma is an obvious characteristic of aromatica fruit (Katayama et al. 2013). Taxonomically, the presence of calyx in the fruit is also considered an important characteristic of var. aromatica (Ohwi 1965). In this review, we follow the nomenclature of Ohwi (1965), i.e., P. ussuriensis Maxim. var. aromatica (Nakai et Kikuchi) Rehd. [for the details of nomenclature, refer to Katayama and Uematsu (2006)] (Ohwi 1965) and P. ussuriensis Maxim. var. hondoensis (Nakai et Kikuchi) Rehd. (Rehder 1920).

Wild populations of $P$. ussuriensis var. hondoensis and var. aromatica, which are distributed in the central part and northern part of the main island of Japan respectively, have different habitats: they grow in deciduous forests at altitudes of $900-1800 \mathrm{~m}$ and $500-1100 \mathrm{~m}$ asl, respectively. Recent taxonomic studies recognized var. aromatica as convarietal with var. ussuriensis because Asian continental (var. ussuriensis sensu stricto) and Japanese (var. aromatica) populations of $P$. ussuriensis could not be distinguished morphologically, whereas var. hondoensis is distinguished by smaller leaves and serrated (not setoso serrated) leaf margins (Iketani and Ohashi 2001, 2003). Still the origins of P. ussuriensis var. hondoensis and var. aromatica in Japan remain unclear.

The morphological discriminating feature between $P$. ussuriensis in Japan and P. pyrifolia is the persistency of calyces of its mature fruit, which are deciduous in P. pyrifolia
(Rehder 1940). However, calyx persistency is unstable, because interspecific hybrids between $P$. ussuriensis and P. pyrifolia with morphologically intermediate traits, arise easily because of cross-compatibility.

Many pear trees with wide morphological variations were discovered in and around the Kitakami Mountains including some that were morphologically intermediate between P. ussuriensis and P. pyrifolia (Katayama and Uematsu 2006). Traditional methods i.e., morphological comparisons, suggested the possible presence of true native populations. However, it was difficult to conclude which is true native because of such a divergent morphology.

To overcome the difficulties in identifying biological taxa or horticultural cultivars only by morphological characters, molecular approaches using nuclear DNA markers, e.g., simple sequence repeat (nSSR), AFLP, or chloroplast DNA (cpDNA) markers representing structural rearrangements and cpSSR have been applied to cultivated and wild trees such as Malus, Sorbus or Pyrus. These methods have revealed the origins, genetic diversity and population genetic structures (Coart et al. 2003, 2006, Fernandez-Fernandez et al. 2006, Gianfranceschi et al.1998, Iketani et al. 2010, Katayama and Uematsu 2003, Katayama et al. 2007, 2012, Kato et al. 2013, Liebhard et al. 2002, Liu et al. 2012, 2013, Nishitani et al. 2005, Robertson et al. 2004, Sawamura et al. 2004, Song et al. 2014, Terakami et al. 2012, Volk et al. 2006, Yamamoto et al. 2001, 2002a, 2002b, Zhong et al. 2014).

SSR markers have been adopted to study relationships between cultivated Chinese Ussurian pears and a few wild Ussurian pears (Cao et al. 2012). Wuyun et al. (2013) revealed the genetic diversity of Chinese wild Ussurian pear using hypervariable regions of cpDNA. A large-scale ecological and population investigation for $P$. ussuriensis in China carried out by nSSR and cpSSR markers indicated suitable conservation units and possible conservation strategies (Wuyun et al. 2015).

A wide range of genetic diversity was revealed for var. aromatica distributed in the northern part of Japan using nSSR and cpDNA markers (Katayama et al. 2007). Based on population genetic structure analysis using nSSR markers, Iketani and Katayama (2012) and Iketani et al. (2010) demonstrated a possible introgression between native var. aromatica and prehistorically naturalized $P$. pyrifolia in the Kitakami Mountains in the northern part of Japan. These results provided useful information for the conservation of genetic resources of the native Ussurian pear in China and in Japan.

In this review, recent advances in molecular studies for the conservation of native Ussurian pears in both China and Japan are introduced. Based on new population structure data, conservation units requiring urgent action to save wild resources are identified. In addition, in order to clarify the origin of var. aromatica in Japan, genetic relationships between P. ussuriensis in China and var. aromatica in Japan are discussed using new population structure data obtained from recent intensive explorations for var. aromatica. 
Population genetic structure of $\boldsymbol{P}$. ussuriensis in China

The distribution of wild Ussurian pears ( $P$. ussuriensis Maxim.) in Inner Mongolia, Jilin, and Heilongjiang provinces was surveyed eleven times between 2009 and 2011 (Ma et al. 2011, Wuyun et al. 2013). A total of 1,518 pear trees from thirteen populations were found in these areas (Fig. 1). Even though the natural habitats of wild Ussurian pears in China have been seriously damaged, we found more than 1500 wild individuals. The number of wild Ussurian pear trees has been decreasing due to desertification in Inner Mongolia and because of continuous land development by humans in Jilin and Heilongjiang (Ma et al. 2011, Wuyun et al. 2013).

In Inner Mongolia, more than 1,000 wild Ussurian pear trees were found in the six natural habitats of Reshui, Qinshan and Tuohe forestry stations in Keshiketengqi, Chifeng City (Table 1). These habitats are located at relatively high altitudes (1,000 to $1,200 \mathrm{~m}$ above sea level).
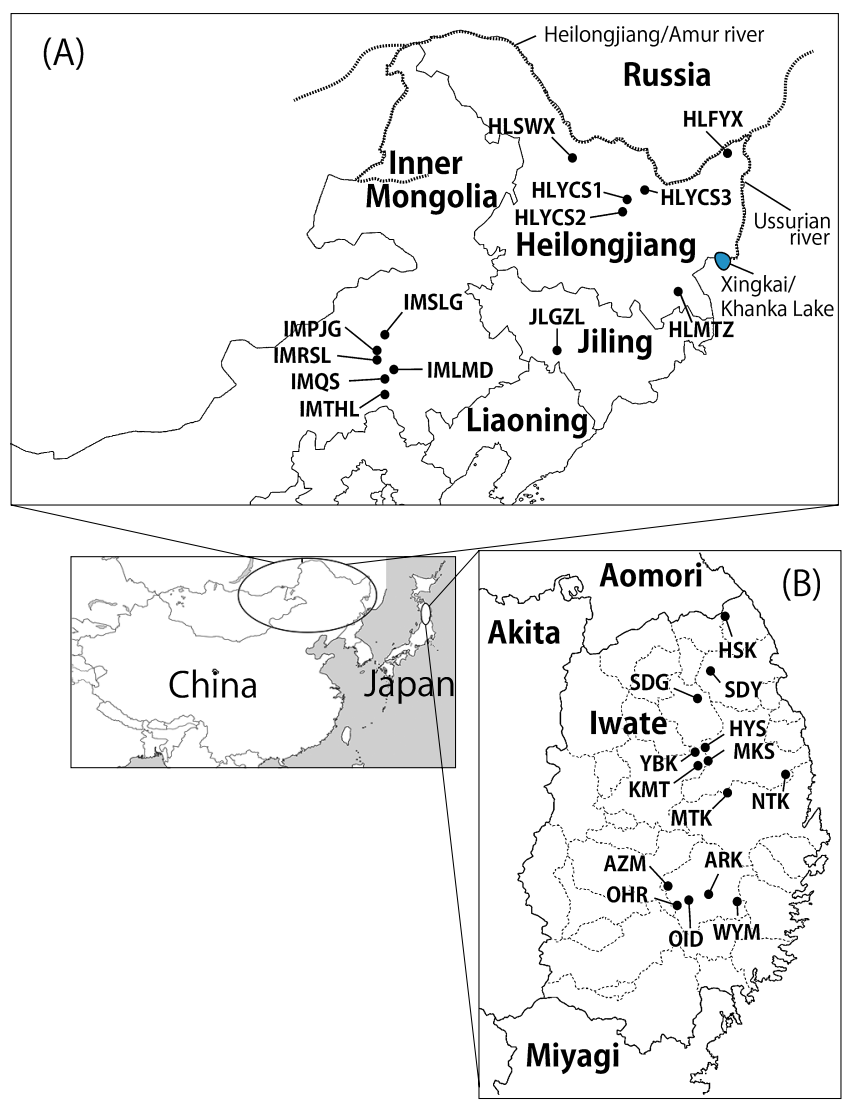

Fig. 1. Geographical distribution of populations originating from Inner Mongolia, Heilongjiang and Jilin province in China (A) and from the Kitakami Mountains in Japan (B). Dotted line in (A) mean Heilongjiang (Amur) and Ussurian rivers along international boundary. Nine populations, SDY, SDG, YBK, KMT, MKS, MTK, NTK, AZM, and ARK in (B) were collected for this review. For detailed information of the other populations, refer to Iketani et al. (2010) and Wuyun et al. (2015).
Trees were distributed over mountains or along valleys. The local people call these habitats 'Shanli gu', which in Chinese means 'mountain pear valley' (Ma et al. 2011).

In Heilongjiang province, more than 500 trees were recognized in six populations (two in Sunwu county, three in Yichun city and a single population in Fuyuan county) (Ma et al. 2011). The area of each population was bigger than that of the Inner Mongolian habitat. In Jilin province, 12 wild trees were distributed within about $10 \mathrm{~km}$ distance between Lishu and Gongzhuling. The wild Ussurian pear habitats in Heilongjiang and Jilin provinces are located at lower altitudes (300 to $600 \mathrm{~m}$ asl) compared to the Inner Mongolian habitat. The tree distribution in Heilongjiang and Jilin was completely different from that in Inner Mongolia i.e., in Heilongjiang and Jilin, trees were usually found close to places of human activity such as around a farmhouse, at a corner of a field or on the edge of a forest but were rarely found in the mountain area (Wuyun et al. 2013).

Wuyun et al. (2015) calculated genetic diversity and genetic structure using nSSR and cpSSR markers for a total of 153 individuals of wild Ussurian pear belonging to thirteen populations (six populations from Inner Mongolia, six from Heilongjiang, and one from Jilin). As a result, the genetic diversity of individuals was revealed to be low as a result of habitat fragmentation (Wuyun et al. 2015). The genetic diversity of the populations from Inner Mongolia (group 1) and the north east of Heilongjiang (group 2 for HLYCS3 and HLFYX) was especially low and there was the possibility of inbreeding. Wild Ussurian pears were divided into five groups based on the Bayesian clustering method using 20 nSSR markers. The populations from Inner Mongolia, the north east of Heilongjiang (group 3 for HLYCS2) especially represented unique genotypes. Two areas, one being the whole area of Inner Mongolia and the other, the north east of Heilongiiang, require urgent conservation such as ex situ conservation, because of their genetic particularity and vulnerability. Four conservation units which include two units corresponding to the two urgently required areas mentioned above, were recognized based on the clustering of nSSR markers, and by geographic factors (Wuyun et al. 2015). Furthermore, to investigate the origin of Chinese wild ussurian pear, the relationships between 25 haplotypes represented by $16 \mathrm{cpSSR}$ markers in wild and cultivated Ussurian pears in China were analyzed by a median-joining network model. Haplotype E which was the most common haplotype in the north east of Heilongjiang with haplotype network was considered to be the divergent center of wild Ussurian pears in China (Wuyun et al. 2015). The wild Ussurian pear in China might have diverged from the north east of Heilongiiang. However, in order to reveal the origin of the Ussurian pear, further analysis, using more wild Ussurian pears collected from the north east and west of Heilongjiang and far east of Russia, is required. 
Table 1. Distribution of 27 populations of $P$. ussuriensis Maxim. in China and P. ussuriensis var. aromatica in Japan

\begin{tabular}{|c|c|c|c|c|c|}
\hline $\begin{array}{l}\text { Population } \\
\text { name }\end{array}$ & Location & $\begin{array}{l}\text { Number of } \\
\text { individual }\end{array}$ & Latitude $\left({ }^{\circ} \mathrm{N}\right)$ & Longitude $\left({ }^{\circ} \mathrm{E}\right)$ & Altitude (m) \\
\hline \multicolumn{6}{|l|}{ China } \\
\hline $\mathrm{IMQS}^{a}$ & $\begin{array}{l}\text { Qingshan forest farm, Keshiketengqi, Chifeng } \\
\text { city, Inner Mongolia }\end{array}$ & 18 & $43^{\circ} 14^{\prime} 61^{\prime \prime}-43^{\circ} 30^{\prime} 00^{\prime \prime}$ & $117^{\circ} 49^{\prime} 96^{\prime \prime}-117^{\circ} 82^{\prime} 00^{\prime \prime}$ & $950.50-1157.00$ \\
\hline $\mathrm{IMTHL}^{a}$ & $\begin{array}{l}\text { Tuohe forest farm, Keshiketengqi, Chifeng city, } \\
\text { Inner Mongolia }\end{array}$ & 26 & $43^{\circ} 04^{\prime} 00^{\prime \prime}-43^{\circ} 07^{\prime} 00^{\prime \prime}$ & $117^{\circ} 52^{\prime} 89^{\prime \prime}-117^{\circ} 89^{\prime} 00^{\prime \prime}$ & $1046.31-1157.00$ \\
\hline $\mathrm{IMPJG}^{a}$ & $\begin{array}{l}\text { Pijianggu, Keshiketengqi, Chifeng citiy, Inner } \\
\text { Mongolia }\end{array}$ & 20 & $43^{\circ} 36^{\prime} 00^{\prime \prime}-43^{\circ} 60^{\prime} 00^{\prime \prime}$ & $117^{\circ} 46^{\prime} 53^{\prime \prime}-117^{\circ} 78^{\prime} 00^{\prime \prime}$ & $1053.51-1106.00$ \\
\hline $\operatorname{IMRSL}^{a}$ & $\begin{array}{l}\text { Reshui forest farm, Keshiketengqi, Chifeng city, } \\
\text { Inner Mongolia }\end{array}$ & 6 & $43^{\circ} 36^{\prime} 16^{\prime \prime}-43^{\circ} 36^{\prime} 18^{\prime \prime}$ & $117^{\circ} 46^{\prime} 74^{\prime \prime}-117^{\circ} 46^{\prime} 77^{\prime \prime}$ & $1003.00-1124.00$ \\
\hline $\operatorname{IMLMD}^{a}$ & $\begin{array}{l}\text { Lamadong, Keshiketengqi, Chifeng city, Inner } \\
\text { Mongolia }\end{array}$ & 10 & $43^{\circ} 25^{\prime} 00^{\prime \prime}-43^{\circ} 42^{\prime} 00^{\prime \prime}$ & $117^{\circ} 82^{\prime} 00^{\prime \prime}-117^{\circ} 83^{\prime} 00^{\prime \prime}$ & $1108.21-1163.25$ \\
\hline $\mathrm{IMSLG}^{a}$ & $\begin{array}{l}\text { Shanligu, Keshiketengqi, Chifeng city, Inner } \\
\text { Mongolia }\end{array}$ & 11 & $43^{\circ} 38^{\prime} 01^{\prime \prime}-43^{\circ} 64^{\prime} 00^{\prime \prime}$ & $117^{\circ} 46^{\prime} 46^{\prime \prime}-117^{\circ} 77^{\prime} 00^{\prime \prime}$ & $1132.62-1271.00$ \\
\hline $\mathrm{HLYCS}^{a}$ & Wumahe, Youhao, Yichun, Heilongjiang & 4 & $47^{\circ} 23^{\prime} 07^{\prime \prime}-47^{\circ} 59^{\prime} 01^{\prime \prime}$ & $128^{\circ} 12^{\prime} 05^{\prime \prime}-128^{\circ} 48^{\prime} 01^{\prime \prime}$ & $230.00-248.00$ \\
\hline $\mathrm{HLYCS}^{a}$ & Cuiluan, Yichun, Heilongjiang & 9 & $47^{\circ} 23^{\prime} 07^{\prime \prime}-47^{\circ} 59^{\prime} 01^{\prime \prime}$ & $128^{\circ} 12^{\prime} 05^{\prime \prime}-128^{\circ} 44^{\prime} 50^{\prime \prime}$ & $300.00-500.00$ \\
\hline $\mathrm{HLYCS}^{a}$ & Meixi, Yichun, Heilongjiang & 10 & $47^{\circ} 53^{\prime} 48^{\prime \prime}-47^{\circ} 53^{\prime} 86^{\prime \prime}$ & $129^{\circ} 31^{\prime} 70^{\prime \prime}-129^{\circ} 31^{\prime} 94^{\prime \prime}$ & $250.21-267.69$ \\
\hline HLFYX $^{a}$ & Fuyuan, Jiamusi, Heilongjiang & 10 & $48^{\circ} 32^{\prime} 84^{\prime \prime}-48^{\circ} 32^{\prime} 85^{\prime \prime}$ & $134^{\circ} 32^{\prime} 37^{\prime \prime}-134^{\circ} 32^{\prime} 44^{\prime \prime}$ & $103.23-115.48$ \\
\hline $\mathrm{HLSWX}^{a}$ & Sunwu, Heihe, Heilongjiang & 7 & $49^{\circ} 03^{\prime} 20^{\prime \prime}-49^{\circ} 39^{\prime} 54^{\prime \prime}$ & $127^{\circ} 40^{\prime} 00^{\prime \prime}-127^{\circ} 56^{\prime} 59^{\prime \prime}$ & $120.00-400.00$ \\
\hline HLMTZ $^{a}$ & Muling, Mudanjiang, Heilongjiang & 10 & $44^{\circ} 41^{\prime} 00^{\prime \prime}-44^{\circ} 41^{\prime} 40^{\prime \prime}$ & $130^{\circ} 32^{\prime} 17^{\prime \prime}-130^{\circ} 28^{\prime} 17^{\prime \prime}$ & $302.00-355.00$ \\
\hline $\mathrm{JLGZL}^{a}$ & Gongzhuling, Jilin & 12 & $43^{\circ} 10^{\prime} 00^{\prime \prime}-44^{\circ} 09^{\prime} 05^{\prime \prime}$ & $124^{\circ} 01^{\prime} 00^{\prime \prime}-125^{\circ} 18^{\prime} 00^{\prime \prime}$ & $400.00-600.00$ \\
\hline $\mathrm{QZL}^{a}$ & Ussurian pear cultivars in China & 29 & & & \\
\hline \multicolumn{6}{|l|}{ Japan } \\
\hline $\mathrm{HSK}^{b}$ & Hashikami Mountain, Hashikami, Aomori & 12 & $40^{\circ} 24^{\prime} 29^{\prime \prime}-40^{\circ} 24^{\prime} 41^{\prime \prime}$ & $141^{\circ} 35^{\prime} 13^{\prime \prime}-141^{\circ} 35^{\prime} 18^{\prime \prime}$ & $510.00-620.00$ \\
\hline $\mathrm{SDY}^{c}$ & Sodeyama, Kuzumaki, Iwate & 13 & $39^{\circ} 59^{\prime} 41^{\prime \prime}-40^{\circ} 01^{\prime} 21^{\prime \prime}$ & $141^{\circ} 30^{\prime} 56^{\prime \prime}-141^{\circ} 31^{\prime} 54^{\prime \prime}$ & $560.00-1070.00$ \\
\hline $\mathrm{HYS}^{b}$ & Hayasaka highland, Iwate & 42 & $39^{\circ} 50^{\prime} 13^{\prime \prime}-39^{\circ} 51^{\prime} 49^{\prime \prime}$ & $141^{\circ} 29^{\prime} 44^{\prime \prime}-141^{\circ} 30^{\prime} 59^{\prime \prime}$ & $840.00-970.00$ \\
\hline $\mathrm{SDG}^{c}$ & Sodegawa, Morioka, Iwate & 12 & $39^{\circ} 54^{\prime} 06^{\prime \prime}-39^{\circ} 59^{\prime} 31^{\prime \prime}$ & $141^{\circ} 25^{\prime} 55^{\prime \prime}-141^{\circ} 27^{\prime} 45^{\prime \prime}$ & $520.00-900.00$ \\
\hline $\mathrm{YBK}^{c}$ & Yabukawa, Morioka, Iwate & 25 & $39^{\circ} 46^{\prime} 51^{\prime \prime}-39^{\circ} 50^{\prime} 58^{\prime \prime}$ & $141^{\circ} 18^{\prime} 58^{\prime \prime}-141^{\circ} 26^{\prime} 59^{\prime \prime}$ & $620.00-700.00$ \\
\hline $\mathrm{KMT}^{c}$ & Karamatusawa, Morioka, Iwate & 26 & $39^{\circ} 44^{\prime} 20^{\prime \prime}-39^{\circ} 50^{\prime} 35^{\prime \prime}$ & $141^{\circ} 24^{\prime} 03^{\prime \prime}-141^{\circ} 25^{\prime} 48^{\prime \prime}$ & $640.00-780.00$ \\
\hline $\mathrm{MKS}^{c}$ & Mukainosawa, Morioka, Iwate & 18 & $39^{\circ} 47^{\prime} 29^{\prime \prime}-39^{\circ} 50^{\prime} 10^{\prime \prime}$ & $141^{\circ} 27^{\prime} 13^{\prime \prime}-141^{\circ} 28^{\prime} 02^{\prime \prime}$ & $600.00-780.00$ \\
\hline $\mathrm{MTK}^{c}$ & Matsukusa, Miyako, Iwate & 27 & $39^{\circ} 38^{\prime} 12^{\prime \prime}-39^{\circ} 48^{\prime} 22^{\prime \prime}$ & $141^{\circ} 26^{\prime} 14^{\prime \prime}-141^{\circ} 32^{\prime} 38^{\prime \prime}$ & $620.00-1100.00$ \\
\hline $\mathrm{NTK}^{c}$ & Natsukari upland, Miyako, Iwate & 26 & $39^{\circ} 42^{\prime} 40^{\prime \prime}-39^{\circ} 43^{\prime} 27^{\prime \prime}$ & $141^{\circ} 39^{\prime} 13^{\prime \prime}-141^{\circ} 40^{\prime} 17^{\prime \prime}$ & $640.00-880.00$ \\
\hline $\mathrm{AZM}^{c}$ & Azumane pasture, Hanamaki, Iwate & 20 & $39^{\circ} 27^{\prime} 40^{\prime \prime}-39^{\circ} 28^{\prime} 07^{\prime \prime}$ & $141^{\circ} 24^{\prime} 35^{\prime \prime}-141^{\circ} 25^{\prime} 06^{\prime \prime}$ & $630.00-860.00$ \\
\hline $\mathrm{OHR}^{b}$ & Ohora pasture, Tono, Iwate & 20 & $39^{\circ} 24^{\prime} 50^{\prime \prime}-39^{\circ} 25^{\prime} 06^{\prime \prime}$ & $141^{\circ} 26^{\prime} 10^{\prime \prime}-141^{\circ} 27^{\prime} 07^{\prime \prime}$ & $580.00-740.00$ \\
\hline $\mathrm{OID}^{b}$ & Oide pasture, Tono, Iwate & 10 & $39^{\circ} 28^{\prime} 29^{\prime \prime}-39^{\circ} 28^{\prime} 38^{\prime \prime}$ & $141^{\circ} 30^{\prime} 13^{\prime \prime}-141^{\circ} 31^{\prime} 19^{\prime \prime}$ & $420.00-520.00$ \\
\hline $\mathrm{ARK}^{c}$ & Arakawa pasture, Tono, Iwate & 12 & $39^{\circ} 27^{\prime} 15^{\prime \prime}-39^{\circ} 29^{\prime} 35^{\prime \prime}$ & $141^{\circ} 32^{\prime} 57^{\prime \prime}-141^{\circ} 36^{\prime} 07^{\prime \prime}$ & $800.00-980.00$ \\
\hline $\mathrm{WYM}^{b}$ & Wayama pasture, Kamaishi, Iwate & 11 & $39^{\circ} 23^{\prime} 31^{\prime \prime}-39^{\circ} 23^{\prime} 44^{\prime \prime}$ & $141^{\circ} 40^{\prime} 58^{\prime \prime}-141^{\circ} 41^{\prime} 30^{\prime \prime}$ & $600.00-800.00$ \\
\hline Local $^{b}$ & local varieties from P. ussuriensis & 14 & & & \\
\hline
\end{tabular}

${ }^{a}$ Refer to Wuyun et al. $(2013,2015)$ for more information.

${ }^{b}$ Refer to Iketani et al. (2010) for more information.

${ }^{c}$ Wild populations collected for this review.

\section{True native populations of $P$. ussuriensis var. aromatica in Japan}

Iketani et al. (2010) investigated the native populations of P. ussuriensis (var. aromatica and var. hondoensis) in Japan using Bayesian statistical inference. Five hypothetical ancestral groups were suggested as a result of analysis using 226 individuals from six regions including Asian Continental local cultivars and wild individuals. Although all of var. hondoensis in Chubu region showed true native genotype, many individuals belonging to the groups of var. aromatica collected from in and around the Kitakami Mountains in northeastern Japan including wild trees and local landraces, were shown to be genetically admixed with $P$. pyrifolia. This result clearly indicated introgression between native var. aromatica and prehistorically naturalized $P$. pyrifolia trees. In addition, commonly observed trees harbouring intermediate characteristics supported this introgression
(Iketani and Katayama 2012, Iketani et al. 2010).

Of the three wild populations (the first is HSK, the second is HYS, and the third is, referred to as TNO by Iketani et al. (2010), including ARK, OHR, and OID in this review) from the Kitakami Mountains, only HYS had a higher proportion of true native individuals than those of the other gene pools. Their present habitats were found in humandisturbed secondary forests or pasturelands in the Kitakami Mountains. Native individuals have likely sustained a genetic influence from cultivated or escaped trees. Thus, this group may have maintained a highly native genetic structure through sheer chance (Iketani et al. 2010). Based on this result, var. aromatica in the Kitakami Mountains has been registered as a threatened species in the Japanese National Red List of Threatened Plants (Ministry of Environment, Japan 2007).

New individuals and habitats around the Kitakami Mountains (Table 1, Fig. 1) have been found as a result of 
more intensive explorations conducted after a report by Iketani et al. (2010). Only about one hundred trees distributed in the central area of the Kitakami Mountains including three populations of HYS, KMT, and MKS as blue cluster (Fig. 3), were identified as true native populations by means of population genetic structure analysis using the same nSSR and cpDNA markers as Iketani et al. (2010) and Katayama et al. (2012) (Unpublished data).

Diversity in floral and fruit morphology of P. ussuriensis in China

In order to demonstrate the relationships between populations of P. ussuriensis in China based on floral and fruit morphology, principal component analysis (PCA) was carried out using six floral and five fruit characteristics (Wuyun et al. 2015). The wild populations in Inner Mongolia and Heilongjiang showed a tendency towards small flowers, short peduncles, and slender petals. Short peduncle length agreed with the length of 1 to $2 \mathrm{~cm}$ for $P$. ussuriensis described by $\mathrm{Gu}$ and Sponberg (2003). In contrast, most Ussurian cultivars had large flowers, long peduncles, and round petals. The flowers of two populations (HLMTZ and HLFYX) from Heilongjiang showed an intermediate flower morphology i.e., relatively large flowers and long peduncles (Wuyun et al. 2015). Based on these results, the fruit morphology of wild Ussurian pear in China could be divided into 2 groups; (1) five populations from Inner Mongolia and one population from Heilongjiang had globular shape and short peduncles; (2) two populations from Heilongiiang had an intermediate elliptical shape and relatively long peduncles.

Differences in floral and fruit morphology between $P$. ussuriensis in China and var. aromatica in Japan

To investigate the origin of var. aromatica in the Kitakami
Mountains, Japan, floral and fruit morphologies of var. aromatica were newly compared with those of $P$. ussuriensis in China in this review. Five flower morphologies i.e., flower diameter, petal length, petal width, petal length/petal width, and peduncle length, and five fruit morphologies i.e., fresh weight, fruit diameter, fruit length, peduncle length, and calyx existence, were measured to perform PCA analysis, for seven populations (IMQS, IMTHL, IMLMD, IMSLG, HLYCS3, HLFYX, and HLMTZ), and 26 Ussurian cultivars from China, and eleven populations (HSK, SDY, HYS, SDG, YBK, KMT, MKS, MTK, AZM, OHR, and ARK) from Japan. For each population, twenty flowers were used for measurements (Fig. 2). The flower and fruit morphology

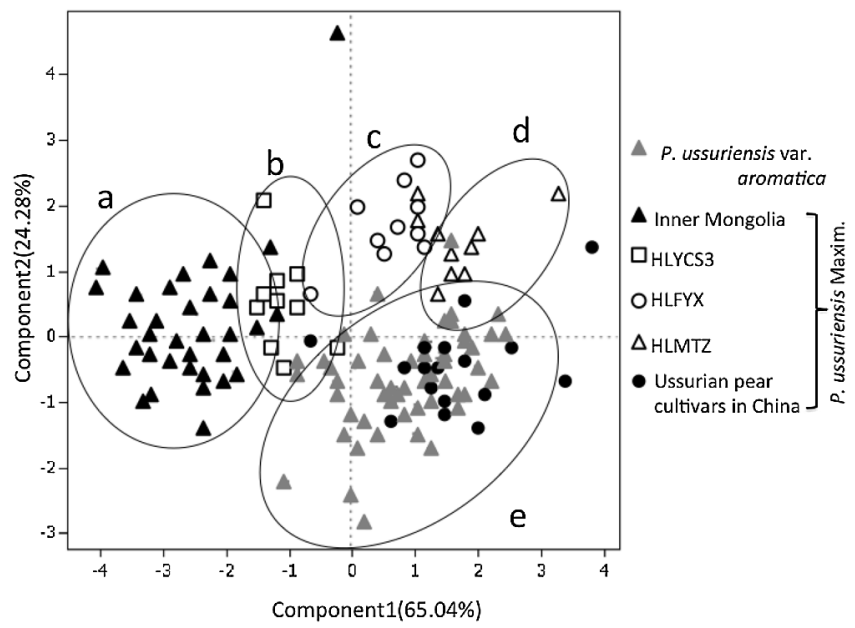

Fig. 2. Principal component scores plotted for principal component 1 and 2 . The representative populations marked by circles were calculated from the measurements of five floral morphological characters. Circle a; Inner Mongolia, b; HLYCS3, c; HLFYX, d; HLMTZ, and e; Chinese Ussurian pear cultivars and P. ussuriensis var. aromatica in Japan.

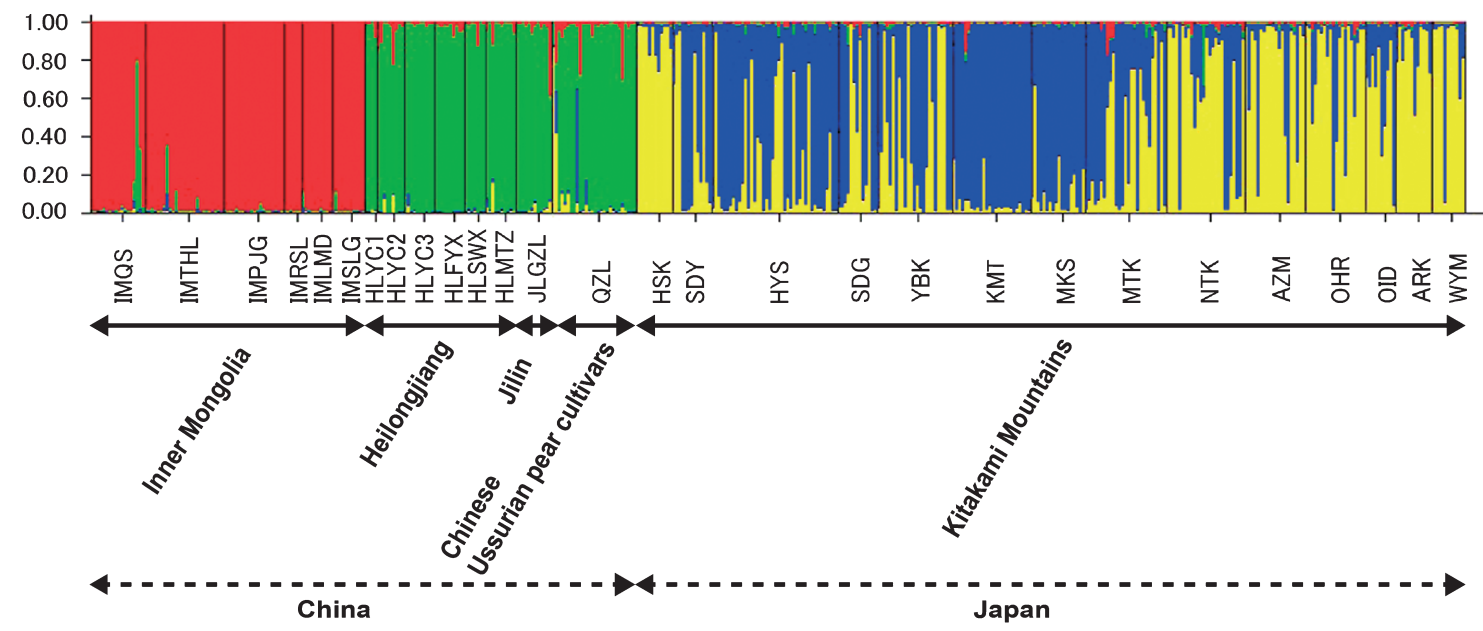

Fig. 3. Percentage membership of genotypes to clusters (q value) inferred at $\mathrm{K}=4$ (independent model) applying all samples without local varieties originated from $P$. ussuriensis var. aromatica to STRUCTURE analysis. Each genotype is represented by a vertical line divided into colored segments. The length of the vertical lines indicates the proportion of genome attributed to the inferred clusters. 
of wild $P$. ussuriensis from China were considerably different from those of var. aromatica from Japan, which showed similarities to Chinese Ussurian cultivars (Fig. 2). Although recent taxonomic studies recognized var. aromatica as convarietal with var. ussuriensis (Iketani and Ohashi 2001, 2003), in this review we use the nomenclature of Ohwi (1965) i.e., two varieties (var. hondoensis and var. aromatica) of $P$. ussuriensis, because wild $P$. ussuriensis from China and var. aromatica from Japan could be distinguished morphologically. Most individuals of the Chinese Ussurian cultivars and var. aromatica from Japan had large flowers, relatively long peduncles, and round petals. In general cultivars have larger flowers compare to wild. But on this occasion, var. aromatica thought to be wild had large flowers and long peduncles. This might arise as a result of the introgression from cultivated Japanese pear to var. aromatica. There might have been an ancestral population of Japanese var. aromatica with small flowers, short peduncles and thin petals (characteristics of wild P. ussuriensis in China) but the present populations might have lost those original features due to intensive introgression.

Genetic diversity of Ussurian pears in China and Japan based on nSSR data

In this review, the genetic diversity within populations of wild Ussurian pears in China inferred from the values of $\mathrm{Na}$, $\mathrm{Ne}$, Ho, and He was much lower when these values were compared to those of Japanese var. aromatica (Table 2). In addition, the genetic diversity of Chinese wild Ussurian pear is low compared to that of Callery pear (P. calleryana), wild apple (Malus sieversii and M. sylvestris), African fruit tree of Rosaceae (Prunus africana), wild grapevine from Spain, and many perennial and outcross species (Cornille et al. 2012, De Andres et al. 2012, Nina et al. 2008, Nybom 2004, Richards et al. 2009).

In spite of low genetic diversity within populations, Wuyun et al. (2015) showed $20.05 \%$ variation among populations of wild Ussurian pears in China by analysis of molecular variance (AMOVA). This value was relatively high compared to those of other species such as $P$. pyrifolia, P. calleryana, and P. pashia (Jiang et al. 2009, Liu et al. $2012,2013)$. The high value $(20.05 \%)$ of AMOVA might reflect the differentiation among populations or restricted gene flow. Alternatively, low genetic diversity might reflect the restrictive gene flow among populations. Therefore both might suggest the same thing i.e., restrictive gene flow and/ or differentiation among populations of Chinese wild Ussurian pears. Gene flow is important to maintain genetic diversity as a counter to the effect of genetic drift arising from habitat fragmentation such as forest degradation caused by climate change in Inner Mongolia or human development in Heilongjiang (Wuyun et al. 2015). But these results suggest that Chinese wild Ussurian pears do have restricted gene flow. Moreover most of the wild populations in China showed high values for $F_{I S}$ (Table 2) which can be attributed
Table 2. Genetic characteristics within 27 populations of the P. ussuriensis Maxim in China and P. ussuriensis var. aromatica

\begin{tabular}{|c|c|c|c|c|c|c|}
\hline \multirow{2}{*}{$\begin{array}{l}\text { Population } \\
\text { name }\end{array}$} & \multicolumn{6}{|c|}{ nSSR markers } \\
\hline & $\mathrm{n}$ & $\mathrm{Na}$ & $\mathrm{Ne}$ & Ho & $\mathrm{He}$ & FIS \\
\hline \multicolumn{7}{|l|}{ China } \\
\hline IMQS & 18 & 4.00 & 2.65 & 0.357 & 0.548 & $0.25836 * *$ \\
\hline IMTHL & 26 & 4.14 & 2.39 & 0.378 & 0.524 & $0.14861 *$ \\
\hline IMPJG & 20 & 3.57 & 2.25 & 0.363 & 0.502 & 0.12909 \\
\hline IMRSL & 6 & 2.57 & 1.78 & 0.300 & 0.425 & 0.21569 \\
\hline IMLMD & 10 & 3.71 & 2.53 & 0.357 & 0.534 & $0.30663 * *$ \\
\hline IMSLG & 11 & 3.29 & 2.20 & 0.322 & 0.534 & $0.30736 * *$ \\
\hline HLYCS1 & 4 & 2.86 & 2.26 & 0.369 & 0.553 & 0.22857 \\
\hline HLYCS2 & 9 & 5.14 & 3.57 & 0.470 & 0.669 & $0.34583 * *$ \\
\hline HLYCS3 & 10 & 4.00 & 2.78 & 0.365 & 0.573 & $0.25865 * *$ \\
\hline HLFYX & 10 & 3.14 & 2.12 & 0.457 & 0.496 & 0.03571 \\
\hline HLSWX & 7 & 4.29 & 3.42 & 0.490 & 0.664 & $0.32344 * *$ \\
\hline HLMTZ & 10 & 4.00 & 2.58 & 0.344 & 0.582 & $0.21918 *$ \\
\hline JLGZL & 12 & 5.71 & 3.65 & 0.436 & 0.638 & $0.25691 * *$ \\
\hline QZL & 29 & 9.00 & 4.38 & 0.594 & 0.745 & $0.08914 *$ \\
\hline \multicolumn{7}{|l|}{ Japan } \\
\hline HSK & 12 & 5.86 & 4.24 & 0.738 & 0.782 & 0.02067 \\
\hline SDY & 13 & 6.29 & 3.74 & 0.692 & 0.692 & -0.09174 \\
\hline HYS & 42 & 9.57 & 4.16 & 0.663 & 0.703 & 0.02208 \\
\hline SDG & 13 & 7.29 & 4.65 & 0.703 & 0.779 & $0.12292 *$ \\
\hline YBK & 25 & 8.00 & 4.75 & 0.697 & 0.762 & 0.07003 \\
\hline KMT & 26 & 6.43 & 3.24 & 0.603 & 0.64 & 0.05127 \\
\hline MKS & 18 & 6.43 & 3.73 & 0.690 & 0.678 & 0.0068 \\
\hline MTK & 27 & 7.86 & 3.97 & 0.649 & 0.726 & 0.05971 \\
\hline NTK & 26 & 7.71 & 4.52 & 0.676 & 0.752 & 0.07558 \\
\hline AZM & 20 & 7.71 & 5.00 & 0.707 & 0.778 & 0.04843 \\
\hline OHR & 20 & 8.71 & 5.52 & 0.786 & 0.801 & -0.02814 \\
\hline OID & 10 & 5.29 & 3.61 & 0.757 & 0.721 & -0.10388 \\
\hline ARK & 12 & 6.71 & 4.32 & 0.869 & 0.791 & -0.08946 \\
\hline WYM & 11 & 7.86 & 4.89 & 0.741 & 0.798 & 0.0538 \\
\hline Local & 14 & 8.57 & 5.98 & 0.816 & 0.829 & -0.07692 \\
\hline
\end{tabular}

Number of alleles $(\mathrm{Na})$, effective number of alleles $(\mathrm{Ne})$, Observed heterozygosity (Ho), and expected heterozygosity ( $\mathrm{He})$ and fixation index $\left(F_{I S}\right)$. Significances of $F_{I S}$ values are given by $* \mathrm{P}<0.05$, ** $\mathrm{P}<$ 0.01. QZL and Locals means the populations of Chinese Ussurian pear cultivars and local varieties of Ussurian pear in Japan.

to non-random mating i.e., inbreeding caused by habitat fragmentation and limited gene flow. The self-incompatibility (S-) locus can usually prevent crossing between closelyrelated individuals and self-pollination, but in small populations, inbreeding such as sister brother mating can occur

The genetic diversity within populations of Japanese var. aromatica inferred from the values of $\mathrm{Na}, \mathrm{Ne}, \mathrm{Ho}$, and $\mathrm{He}$ was higher than that of Chinese wild Ussurian pears (Table 2). This might reflect introgression from P. pyrifolia to var. aromatica as described by Iketani et al. (2010). On the other hand, the genetic differentiation among populations in var. aromatica estimated by AMOVA was as low as $7.20 \%$ (Tachibana et al. 2009). This value was similar to that of P. communis (Volk et al. 2006), but lower than that of Chinese wild Ussurian pears $(20.05 \%)$. The difference in AMOVA values between Japanese var. aromatica populations and Chinese wild Ussurian pear populations might reflect differences in geographical distance between populations i.e., closely distributed in Japan or widespread in China. 
The pairwise $F_{S T}$ values obtained for each of the Chinese wild Ussurian pear populations were higher than the $F_{S T}$ values obtained for each of the var. aromatica populations in Japan (data not shown). This result agrees with the result obtained by analysis of molecular variance (AMOVA) i.e., high value for Chinese wild Ussurian pear populations vs. low value for Japanese var. aromatica populations.

Bayesian statistical inference of the population structure

The Bayesian model-based clustering programs STRUCTURE 2.3.4 (Pritchard et al. 2010) were employed to detect population structure and assign individuals to groups using the 20 nSSR markers as used by Wuyun et al. (2015) under the admixture model and the option of correlated allele frequencies between populations of $P$. ussuriensis endemic in China and Japan. The cluster number (K) was set to vary from 1 to 15 . The model was run as 10 independent simulations for each K and used a burn-in length of 100,000 and a run length of 1,000,000 MCMC iterations. The relationships between the $\mathrm{K}$ value and (i) the data likelihood of $\mathrm{K}$ and (ii) the ad hoc statistic $\Delta \mathrm{K}$ as recommended by Evanno et al. (2005) were plotted. The $\Delta \mathrm{K}$ showed largest value at $\mathrm{K}=4$. The plot of the average log-likelihood values reached a plateau at $\mathrm{K}=4$ (data not shown). Values of $\ln \mathrm{P}(\mathrm{X} \mid K)$ were similar in the independent and correlated models. At $\mathrm{K}=4$, P. ussuriensis in China and var. aromatica in Japan were divided into two groups (Fig. 3). $\mathrm{K}=4$ indicates a reasonable result; (1) Inner Mongolia with red cluster (IMQS, IMTHL, IMPJG, IMRSL, IMLMD, and IMSLG), (2) Heilongjiang with green cluster (HLYCS1, HLYCS2, HLYCS3, HLFYX, HLSWX, and HLMTZ), Jilin; JLGZL (green), and QZL; Ussurian pear cultivars in China (green), (3) Northern and Southern areas of Kitakami Mountains with yellow and blue clusters (HSK, SDY, SDG, YBK, MTK, NTK, AZM, OHR, OID, ARK, and WYM) in Japan, (4) central area of the Kitakami Mountains with blue cluster (HYS, KMT, and MKS) in Japan. Populations from Inner Mongolia and Heilongjiang in China were made up of relatively uniform gene pools respectively, though IMQS and QZL, which includes Ussurian cultivars, formed slight admixtures. This result agrees with a previous report indicating low genetic diversity in Chinese Ussurian pear populations (Wuyun et al. 2015). STRUCTURE analysis of $20 \mathrm{nSSR}$ markers using 226 individuals of, wild, seemingly wild, and cultivated trees in Japan, revealed var. aromatica in Japan was genetically admixed with two genetic clusters: one is the true native var. aromatica and the other is a prehistorically introduced P. pyrifolia in the Kitakami Mountains. This result agreed well with Iketani et al. (2010), who concluded that true native populations of var. aromatica existed at HYS. In this review, population structure analysis using more populations from the Kitakami Mountains determined blue dominant clusters representing true native populations (HYS, KMT, and MKS) which occur in the central area of the Kita- kami Mountains (Fig. 3). Clusters admixed with blue and yellow suggest introgressions from P. pyrifolia in the northern and southern areas of the Kitakami Mountains (Fig. 3). The genetic structures of $P$. ussuriensis in China and var. aromatica in Japan were completely different even though both were constructed from two clusters. Chinese Ussurian cultivars, QZL, were present in the same cluster (green) of wild populations from Heilongjiang and Jilin in China.

Genetic relationships between $P$. ussuriensis in China and $P$. ussuriensis var. aromatica in Japan

In this review, twenty seven populations of Ussurian pears from China and Japan, and two groups including cultivars and local varieties were separated into five clades on an unrooted NJ tree shown in Fig. 4 using 20 nSSR markers as used by Wuyun et al. (2015). The tree topology was identical to that inferred by phylogenetic analysis reported previously

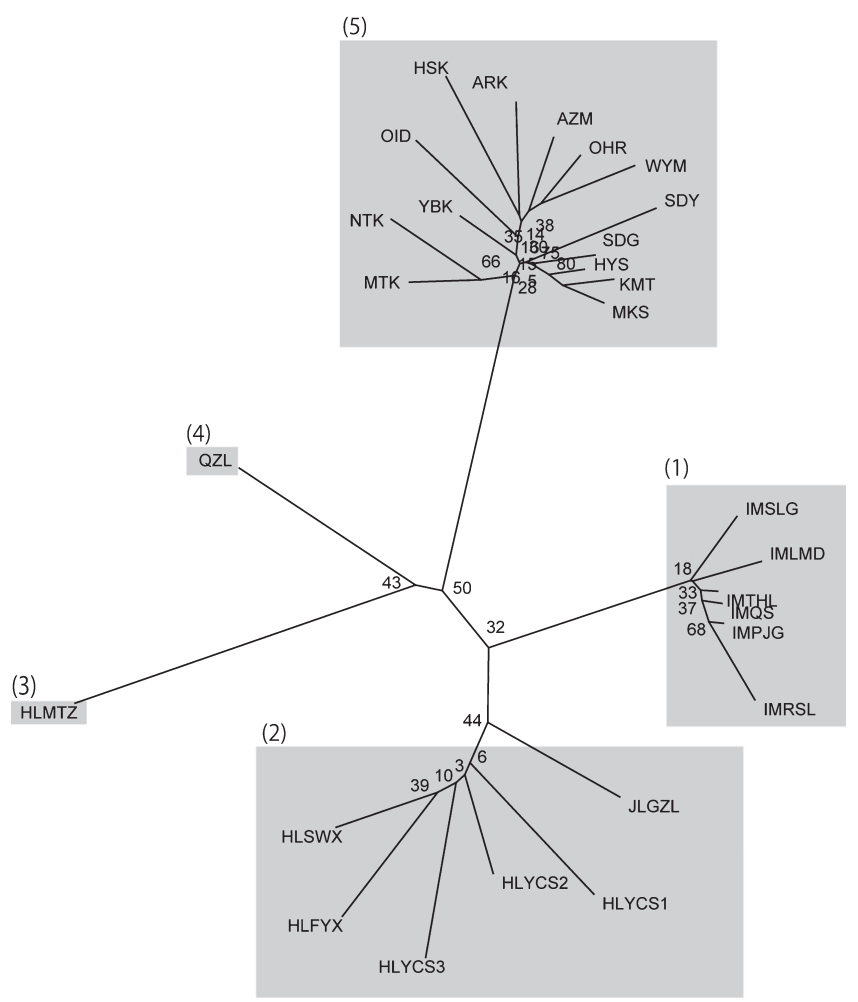

Fig. 4. Unrooted neighbor-joining tree based on Nei's DA distance value among populations. The number of points of divergence represents bootstrap values. The six populations (IMQS, IMTHL, IMPJG, IMRSL, IMLMD, and IMSLG) originating from Inner Mongolia. (2) The 5 populations (HLYCS3, HLFYX, HLSWX, HLYCS2, and HLYCS1) from Heilongjiang. (3) HLMTZ from Mudanjiang, Heilongjiang. (4) The cultivated Ussurian pears (QZL) were combined. (5) The 14 populations (HSK, SDY, HYS, SDG, YBK, KMT, MKS, MTK, NTK, AZM, OHR, OID, ARK, and WYM) originating from Kitakami Mountains in Japan. 
(Wuyun et al. 2015). The six populations (IMQS, IMTHL, IMPJG, IMRSL, IMLMD, and IMSLG) originating from Inner Mongolia, were all closely related. The five populations (HLYCS3, HLFYX, HLSWX, HLYCS2, and HLYCS1) from Heilongjiang and one population (JLGZL) from Jilin also showed relatively close relationships. The six populations from Inner Mongolia and the five populations from Heilongjiang were distantly positioned from each other.

One population (HLMTZ) from Mudanjiang, Heilongjiang was distantly related to the other populations in Heilongjiang. Based on STRUCTURE analysis, Wuyun et al. (2015) indicated that the HLMTZ population was completely different from other populations in Heilongjiang. The present result of PCA for flower morphology shows that the HLMTZ population and some Ussurian pear cultivars share the characteristics of relatively large petals and long peduncles (Fig. 2). In Mudanjiang City, where the population of HLMTZ is located, Ussurian pears have a long history of cultivation, so that introgression of Ussurian pear cultivars into wild $P$. ussuriensis might have occurred in HLMTZ over time. On the other hand this population was also distantly related to QZL which consists of Chinese Ussurian cultivars (Fig. 4).

\section{Conclusions and Prospects}

Based on population structure and phylogenetic analyses, $P$. ussuriensis var. aromatica and $P$. ussuriensis (wild Ussurian pear in China) was revealed to be genetically divergent (Figs. 3, 4). They might have differentiated sometime between the Pliocene and the Pleistocene as a consequence of geographical disjunction caused by climate fluctuation represented by the glacial/interglacial. However, although the natural habitat of $P$. ussuriensis var. aromatica in Japanese was found, its origin still remains unclear. Also in order to reveal the origin of $P$. ussuriensis in China, more intensive habitat explorations in the north east and west of Heilongjiang in China and the far east of Russia is required.

Molecular studies for genetic diversity and genetic structure of the native Ussurian pears populations both in China and Japan suggested that urgent conservation is required for the following populations i.e., four conservation units from Inner Mongolia and the north east of Heilongjiang (four groups shown in Wuyun et al. 2015) and three true native populations such as HYS, KMT, and MKS in the central area of the Kitakami Mountains in Japan shown in this review. Individuals in these populations should be preserved with both of in situ and ex situ conservations.

\section{Acknowledgements}

This research was supported by the National Natural Science Foundation of China (31000309) and Grant-in-Aid (25430191, 17510196) for Scientific Research from the Ministry of Education, Science and Culture, Japan.

\section{Literature Cited}

Bell, R.L., H.A.Quamme, R.E.C.Layne and R.M. Skirvin (1996) Pears. In: Janick, J. and J.N. Moore (eds.) Fruit breeding, volume I: tree and tropical fruit. Wiley, New York, pp. 441-514.

Campbell, C.S., R.C.Evans, D.R.Morgan, T.A.Dickinson and M.P. Arsenault (2007) Phylogeny of subtribe Pyrinae (formerly the Maloideae, Rosaceae): Limited resolution of a complex evolutionary history. Plant Syst. Evol. 266: 119-145.

Cao, Y., L. Tian, Y. Gao and F. Liu (2012) Genetic diversity of cultivated and wild Ussurian pear (Pyrus ussuriensis Maxim.) in China evaluated with M13-tailed SSR markers. Genet. Resour. Crop Evol. 59: 9-17.

Coart, E., X. Vekemans, M.M. Smulders, I. Wagner, J. Van Huylenbroeck, E. Van Bockstaele and I. Roldán-Ruiz (2003) Genetic variation in the endangered wild apple (Malus sylvestris (L.) Mill.) in Belgium as revealed by amplified fragment length polymorphism and microsatellite markers. Mol. Ecol. 12: 845-857.

Coart,E., S. Van Glabeke, M.De Loose, A.S.Larsen and I. RoldánRuiz (2006) Chloroplast diversity in the genus Malus: new insights into the relationship between the European wild apple (Malus sylvestris (L.) Mill.) and the domesticated apple (Malus domestica Borkh.). Mol. Ecol. 15: 2171-2182.

Cornille,A., P. Gladieux, M.J.Smulders, L.Roldán-Ruiz, F.Laurens, B.Le Cam, A. Nersesyan, J.Clavel, M. Olonova, L. Feugey et al. (2012) New insight into the history of domesticated apple: secondary contribution of the European wild apple to the genome of cultivated varieties. PLoS Genet. 8: e1002703.

De Andres, M.T., A. Benito, G.Perez-Rivera, R. Ocete, M.A.Lopez, L. Gaforio, G.Munoz, F.Cabello, J.M.Martinez Zapater and R. Arroyo-Garcia (2012) Genetic diversity of wild grapevine populations in Spain and their genetic relationships with cultivated grapevines. Mol. Ecol. 21: 800-816.

Evanno, G., S. Gegnaut and J. Goudet (2005) Detecting the number of clusters of individuals using the software STRUCTURE: a simulation study. Mol. Ecol. 14: 2611-2620.

Fernandez-Fernandez, F., N.G. Harvey and M.James (2006) Isolation and characterization of polymorphic microsatellite markers from European pear (Pyrus communis L.). Mol. Ecol. 6: 1039-1041.

Gianfranceschi, L., N. Seglias, R. Tarchini, M. Komjanc and C. Gessler (1998) Simple sequence repeats for the genetic analysis of apple. Theor. Appl. Genet. 96: 1069-1076.

Gu, T.C. and S.A. Sponberg (2003) Pyrus. In: Wu, Z.Y., P.H. Raven and D.Y.Hong (eds.) Flora of China, $9^{\text {th }}$ edn. Science Press. Beijing, pp. 173-179.

Iketani, H. and H. Ohashi (2001) Pyrus. In: Iwatsuki, K., D.E. Boufford and H. Ohba (eds.) Flora of Japan IIb. Angiospermae Dicotyledoneae Archichlamydeae. Kodansha, Tokyo, pp. 123-124.

Iketani, H. and H. Ohashi (2003) Taxonomy and distribution of Japanese populations of Pyrus ussuriensis Maxim. (Rosaceae). J. Jpn. Bot. 78: 119-134

Iketani,H., T.Yamamoto, H.Katayama, C.Uematsu, N.Mase and Y. Sato (2010) Introgression between native and prehistorically naturalized (archaeophytic) wild pear (Pyrus spp.) populations in Northern Tohoku, Northeast Japan. Conserv. Genet. 11: 115-126.

Iketani, H. and H. Katayama (2012) Introgression and long-term naturalization of archaeophytes into native plants underestimated risk of hybrids. In: Povilitis, T. (ed.) Topics in Conservation Biology, In-Tech Educational and Publishing, pp. 43-56.

Iketani, H., H. Katayama, C. Uematsu, N. Mase, Y. Sato and T. Yamamoto (2012) Genetic structure of East Asian cultivated pears (Pyrus spp.) 
and their reclassification in accordance with the nomenclature of cultivated plants. Plant Syst. Evol. 298: 1689-1700.

Jiang, Z., F. Tang, H. Huang, H.Hu and Q. Chen (2009) Assessment of genetic diversity of Chinese sand pear landraces (Pyrus pyrifolia Nakai) using simple sequence repeat markers. HortScience 44: 619-626.

Jiao, P.J., T.J. Guo, F.Y.Zhang, J.H.Li, W.P. Lu, Z.G. Liu and Z.G. Guo (2000) Research on the evaluation of main characters of the Pyrus ussuriensis Maxim. Special Wild Economic Animal and Plant Research 1: 24-28.

Kang, X., T. Wuyun, Y.Cao and L. Tian (2010) Analysis of aroma components in ripe fruits of Pyrus ussuriensis. Hunan Forest. Sci. Tech. 2: $1-4$.

Katayama, H. and C. Uematsu (2003) Comparative analysis of chloroplast DNA in Pyrus species: physical map and gene localization. Theor. Appl. Genet. 106: 303-310.

Katayama, H. and C. Uematsu (2006) Pear (Pyrus species) genetic resources in Iwate, Japan. Genet. Resour. Crop Evol. 53: 483-498.

Katayama, H., S.Adachi, T. Yamamoto and C. Uematsu (2007) A wide range of genetic diversity in pear (Pyrus ussuriensis var. aromatica) genetic resources from Iwate, Japan revealed by SSR and chloroplast DNA markers. Genet. Resour. Crop Evol. 54: 1573-1585.

Katayama, H., M. Tachibana, H.Iketani, S.L.Zhang and C.Uematsu (2012) Phylogenetic utility of structural alterations found in the chloroplast genome of pear: hypervariable regions in highly conserved genome. Tree Genet. Genomes 8: 313-326.

Katayama,H., M. Ohe and E.Sugawara (2013) Diversity of odoractive compounds from local cultivars and wild accessions of Iwateyamanashi (Pyrus ussuriensis var. aromatica) revealed by Aroma Extract Dilution Analysis (AEDA). Breed. Sci. 63: 86-95.

Kato, S., A. Imai, R. Nishioka and Y. Mukai (2013) Population genetic structure in a threatened tree, Pyrus calleryana var. dimorphophylla revealed by chloroplast DNA and nuclear SSR locus polymorphisms. Conserv. Genet. 14: 983-996.

Li, G., H.Jia, R. Wu and Y.Teng (2013) Changes in volatile organic compound composition during the ripening of 'Nanguoli' pears (Pyrus ussuriensis Maxim) harvested at different growing locations. J. Hort. Sci. Biotechnol. 88: 563-570.

Li, T., X.Li, D. Tan, Z. Jiang, Y.Wei, J.Li, G. Du and A. Wang (2014) Distinct expression profiles of ripening related genes in the 'Nanguo' pear (Pyrus ussuriensis) fruits. Sci. Hortic. 171: 78-82.

Liebhard, R., L. Gianfranceschi， B. Koller, C.D. Ryder, R. Tarchini, E. Van De Weg and C. Gessler (2002) Development and characterisation of 140 new microsatellites in apple (Malus $\times$ domestica Borkh.). Mol. Breed. 10: 217-241.

Liu, J., X.Zheng, D. Potter, C. Hu and Y. Teng (2012) Genetic diversity and population structure of Pyrus calleryana (Rosaceae) in Zhejiang province, China. Biochem. Syst. Ecol. 45: 69-78.

Liu, J., P. Sun, X. Zheng, D. Potter, K. Li, C. Hu and Y.Teng (2013) Genetic structure and phylogeography of Pyrus pashia L. (Rosaceae) in Yunnan Province, China, revealed by chloroplast DNA analyses. Tree Genet. Genomes 9: 433-441.

Ma, T., T. Wuyun, W. Deng, K. Xiu and L. Jian (2011) Investigation on wild Pyrus ussuriensis Maxim. resources of Chifeng area in Inner Mongolia. Guangdong Agricultural Science. 2.

Maximowicz, C.J. (1859) Primitiae florae amurensis. Mémoires présentés a l'académie impériale des sciences de St.-Pétersbourg par divers savants et lus dans ses assemlées, 9: 1-504.

Ministry of the Environment, the Government of Japan (2007) The updated japanese red lists on mammals, brackish-water/freshwater fishes, insects, shellfish, and plants I and II.
Nakai,T. (1918) Notulae ad plantas japonicae et koreae XVI. Bot. Mag. Tokyo 32: 28-37.

Nina, F., B. Carsten and B.G. Katrin (2008) Human disturbance reduces genetic diversity of an endangered tropical tree, Prunus africana (Rosaceae). Conserv. Genet. 9: 317-326.

Nishitani, C., T. Shimizu, S. Ohta, T. Kimura, Y. Sawamura, T. Hayashi and T. Yamamoto (2005) Functional genomics in pear I. cDNA libraries derived from various tissues of the Japanese pear 'Housui'. Abstr. Plant and Animal Genome XIII Conference. 198.

Nybom,H. (2004) Comparison of different nuclear DNA markers for estimating intraspecific genetic diversity in plants. Mol. Ecol. 13: $1143-1155$.

Ohwi, J. (1965) Pyrus. In: Flora of Japan. Smithsonian Institution, Washington DC, p. 549.

Pritchard,J.K., W.Wen and D.Falush (2010) Documentation for STRUCTURE software: version 2.3. Available from http://pritch. bsd.uchicago.edu/structure.html.

Pu, F. and Y. Wang (1963) Pomology of China. Vol. 3. Pears. Shanghai: Shanghai Science and Technology Press.

Qin, G., S. Tao, Y. Cao, J. Wu, H. Zhang, W. Huang and S. Zhang (2012) Evaluation of the volatile profile of 33 Pyrus ussuriensis cultivars by HS-SPME with GC-MS. Food Chem.134: 2367-2382.

Rehder,A. (1920) New species, varieties and combinations from the herbarium and the collections of the Arnold Arboretum. J. Arn. Arb. 2: 42-64.

Rehder,A. (1940) A manual of cultivated trees and shrubs hardy in North American exclusive of the subtropical and warmer temperate regions, 2nd edn. Macmillan, New York, p. 403.

Report of the Chinese Academy of Agricultural Science (1963) China fruit records, Shanghai Technology House.

Richards, C.M., G.M.Volk, A.A.Reilley, A.D.Henk, D.R.Lockwood, P.A. Reeves and P.L.Forsline (2009) Genetic diversity and population structure in Malus sieversii, a wild progenitor species of domesticated apple. Tree Genet. Genomes 5: 339-347.

Robertson,A., A.C.Newton and R.A.Ennos (2004) Multiple hybrid origins genetic diversity and population genetic structure of two endemic Sorbus taxa on the Isle of Arran, Scotland. Mol. Ecol. 13: 123-134.

Sawamura, Y., T. Saito, N. Takeda, T. Yamamoto, T. Kimura, T. Hayashi and K. Kotobuki (2004) Identification of parentage of Japanese pear 'Housui'. J. Japan. Soc. Hort. Sci. 73: 511-518.

Song, Y., L. Fan, H. Chen, M.Zhang, Q. Ma, S.Zhang and J. Wu (2014) Identifying genetic diversity and a preliminary core collection of Pyrus pyrifolia cultivars by a genome-wide set of SSR markers. Sci. Hortic. 167: 5-16.

Tachibana, M., H. Katayama, Y. Iketani, T. Yamamoto and C. Uematsu (2009) Evaluation of genetic diversity of Iwate yamanashi (Pyrus ussuriensis var. aromatica) populations revealed by DNA markers and morphological characters. Breed. Res. 11 (Suppl. 1): 191.

Terakami, S., Y. Matsumura, K. Kurita, H. Kanamori, Y. Katayose, T. Yamamoto and H. Katayama (2012) Complete sequence of the chloroplast genome from pear(Pyrus pyrifolia): genome structure and comparative analysis. Tree Genet. Genomes 8: 841-854.

Volk, G.M., C.M.Richards, A.D.Henk, A.A.Reilley, N.V. Bassil and J.D. Postman (2006) Diversity of wild Pyrus communis based on microsatellite analyses. J. Amer. Soc. Hort. Sci. 131: 408-417.

Wuyun, T., T. Ma, C. Uematsu and H. Katayama (2013) A phylogenetic network of wild Ussurian pears (Pyrus ussuriensis Maxim.) in China revealed by hypervariable regions of chloroplast DNA. Tree Genet. Genomes 9: 167-177.

Wuyun, T., H.Amo, J.Xu, T. Ma, C. Uematsu and H. Katayama (2015) 
Population structure of and conservation strategies for wild Pyrus ussuriensis Maxim. in China. PLoS ONE 10: e0133686.

Yamamoto, T., T. Kimura, Y. Sawamura, K. Kotobuki, Y. Ban, T. Hayashi and N. Matsuta (2001) SSRs isolated from apple can identify polymorphism and genetic diversity in pear. Theor. Appl. Genet. 102: 865-870.

Yamamoto, T., T.Kimura, Y.Sawamura, T.Manabe, K. Kotobuki, T. Hayashi, Y. Ban and N. Matsuta (2002a) Simple sequence repeats for genetic analysis in pear. Euphytica 124: 129-137.

Yamamoto, T., T.Kimura, M. Shoda, T.Imai, T.Saito, Y.Sawamura, K. Kotobuki, T.Hayashi and N.Matsuta (2002b) Genetic linkage maps constructed by using an interspecific cross between Japanese and European pears. Theor. Appl. Genet. 106: 9-18.

Yü,T.T. (1979) Taxonomy of the fruit tree in China, Agriculture Press, Beijing, China.

Yü, T.T. and T.C.Ku (1974) Pyrus. In: Yü, T.T. (ed.) Flora Reipublicae Popularis Sinicae, Vol. 36, Science Press, Beijing, China, pp. 354372.

Zhong, Y., P. Sun, J.Liu, X. Yue, K.Li and Y.Teng (2014) Genetic diversity and population structure of seedling populations of Pyrus pashia. Plant Mol. Biol. Rep. 32: 644-651. 